\title{
Peculiarities of Thermal Regime Formation of Near-Bottom Lake Water
}

\author{
Nikolaj Tarasiuk ${ }^{1}$, Anastasija Moisejenkova ${ }^{2}$, Milda Pečiuliené², \\ Dainius Jasaitis ${ }^{2 *}$, Aloyzas Girgždys ${ }^{2}$ \\ ${ }^{1}$ Institute of Physics of Center for Physical Sciences and Technology, \\ Savanoriu Ave. 231 LT-02300, Vilnius, Lithuania \\ ${ }^{2}$ Vilnius Gediminas Technical University, Sauletekio al. 11, LT-10223, Vilnius, Lithuania
}

Received: March 10, 2015

Accepted: September 15, 2015

\begin{abstract}
Our paper presents data on the annual course of the temperatures of surface sediments in deep bottom areas of a lake that has been assigned a "moderately-warm" designation. It is shown that the highest temperatures of those sediments are reached in autumn when near-bottom waters are involved with the processes of the gravitational mixing of the water column. Mixing conditions of the water column were estimated using additional information on the vertical profiles of standard water variables $(\mathrm{pH}$, oxygen concentration, and conductivity). It is shown that depending on the amount of heat stored in the sediments of the deep bottom areas and the thermodynamic processes of its redistribution, the lake may be designated "super-warm" or "moderately-warm." This implies that existing thermal classification of lakes is too formal and does not account for the complexity of thermodynamic processes of heat redistribution. Measurement data is evidence of the implication of the inflows from the bottom-feeding sources in the formation of the highly mineralized near-bottom water layer in those bottom areas.
\end{abstract}

Keywords: lake, thermal regime, classification, bottom-feeding sources

\section{Introduction}

The thermal structure of lakes varies, but special consistent patterns are typical for them. Continuous processes in the lakes (thermodynamic, hydrophysical, and others) let scientists group lakes according to the selected criteria. The most common classifications are according waterhole origin, chemical structure of water, slope, quality of the water, flush, intensity of water circulation, etc. [1,2]. Many scientists analyze the problems that relate to chemical pollution of the water of lakes, research thermal processes of the sediments at the bottom of the lakes [3], and more. Currently there is lack of information about the thermal regime of near-bottom water peculiarity. It is known that

*e-mail: dainius.jasaitis@vgtu.lt thermodynamic processes in the lakes are influenced mostly by the amount of heat received from the atmosphere, the quantity of the underground water, and ground sediment thickness. Analysing thermodynamic characteristics of the thermal regimes of the near-bottom waters during various seasons is actual.

The thermal regime of lakes is a key parameter in the physics of aquatic system processes. Increasing temperature accelerates biogeochemical cycles and lake metabolism. The stratified season in lakes is important for water fluxes, aquatic habitat, and biodiversity. Observed in recent years, warmer winters will further lead to longer stratified seasons and higher lake water temperatures, which may eventually lead to lower oxygen levels, decreased redox potential, greater microbial decomposition, and an increased release of nutrients and contaminants from the 
bottom sediments [4]. Furthermore, [5] there is improved classification concerning the importance of the near-bottom water temperatures in lakes in winter. According to that classification, four types of lakes were defined as:

a) "super-warm," where temperatures of the near-bottom waters in winter are always above $4^{\circ} \mathrm{C}$

b) "warm," where those temperatures were equal to $4^{\circ} \mathrm{C}$

c) "moderately-warm," where temperatures vary in the 3$4^{\circ} \mathrm{C}$ range

d) "cold" lakes, where temperatures are always below $3^{\circ} \mathrm{C}$.

The aim of the present study is to reveal the causes of the annual variations of temperature of the near-bottom waters in the "moderately-warm" lakes and to show that such a thermal regime is based on the thermodynamic processes of heat redistribution between the sediments of the deep bottom area of the lake and the water column.

\section{Materials and Methods}

When choosing a lake for research it is important to know that while doing vertical standard measurements the thermal structure of the lake is influenced not only by meteorology (undercurrents, thickness of the ground sediments, etc.). It is very important to evaluate all factors that determine the thermal regime variation of the lakes.

One typical lake that belongs to this group is Lake Tapeliai (54 $\left.46^{\prime} 28^{\prime \prime} \mathrm{N}, 25^{\circ} 26^{\prime} 45^{\prime \prime} \mathrm{E}\right)$, located $17 \mathrm{~km}$ northeast of Vilnius, Lithuania, in a wooded region at $136.1 \mathrm{~m}$ a.s.1. (Fig. 1). It is a beginning water body in the lake chain connected by a brook. The lake is eutrophic. Its banks are rushgrown with a marshy zone formed at a brook outflow area.

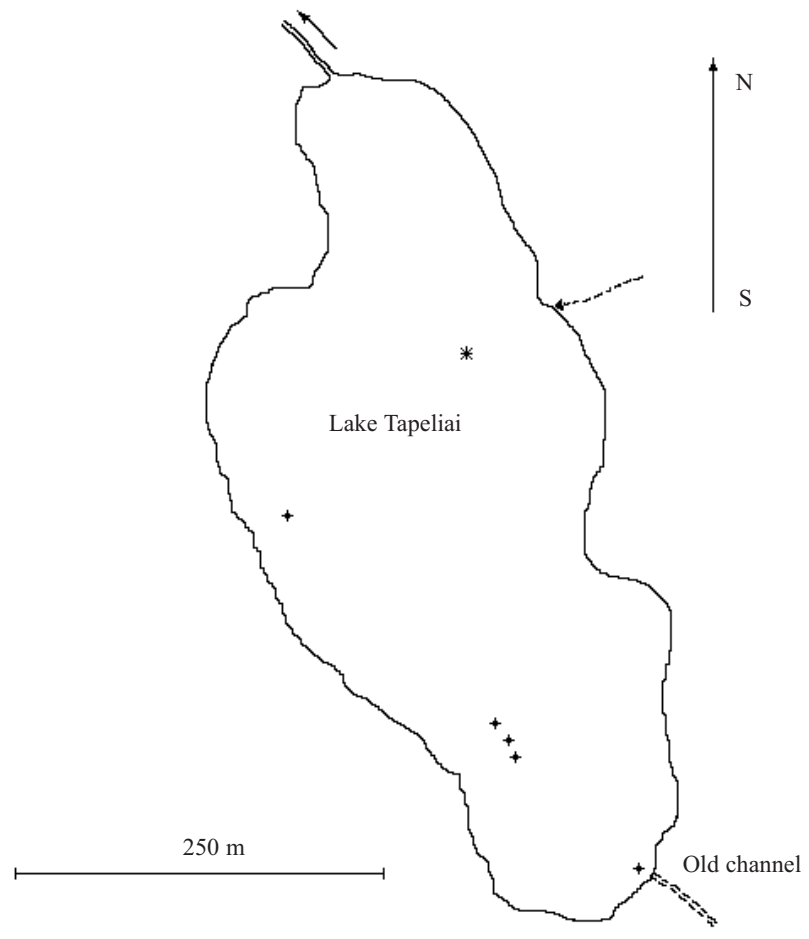

Fig. 1. Schema of Lake Tapeliai; $*$ - a measurement site in the deepest part of the lake, + - location of the bottom-feeding sources, dotted arrow - temporal inflow from a swamp.
The outflows are seasonally dependent and vary in the range of 7-80 L $\cdot \mathrm{s}^{-1}$. Sometimes a small beaver dam controls the water level of the lake.

The basin of the lake is of glacier origin (groove type). It consists of four sections:

a) a southern shallow terrace (depths $\sim 4-5 \mathrm{~m}$ )

b) the central deepest part of the lake (depths $\sim 7-9 \mathrm{~m}$ )

c) a northern terrace with a gradual bottom deepening from $\sim 1.5$ down to $\sim 6 \mathrm{~m}$ depths

d) a small bottom terrace in the western side of the lake (depths 5-6 m).

Apart from the watershed, the lake is fed by underwater sources. They are located in three distinct areas:

a) near the western bank of the southern terrace at the 4-4.5 $\mathrm{m}$ depth

b) at the southwestern corner of the central part of the lake

c) near the southern edge of the lake in the vicinity of the old drainage channel, which connected earlier Lake Tapeliai with Red Lake (5446'11"N, 2527'23"E) [6].

During flood periods (in spring and after long-term rains), the lake is fed additionally by the temporal discharge with colored water (shown by the dotted arrow, Fig. 1) from a swamp. The surface area of the lake is equal to $\sim 0.126 \mathrm{~km}^{2}$, drainage basin - $0.7 \mathrm{~km}^{2}$ [7]. The typical amount of dry materials in the surface layer of the sapropelic-type sediments in the lake varies mainly in the range 0.020 $0.036 \mathrm{~kg} \cdot \mathrm{L}^{-1}$. The organic content of the sediments determined as a loss on ignition is shown to increase with sediment depth (down to $30-35 \mathrm{~cm}$ ) and varies in the range of $50-70 \%$. The thickness of the sediment layer measured in the northern terrace increases with the bottom depth. It varies from $\sim 1.5 \mathrm{~m}$ near the northern rush-grown bank up to $\sim 4 \mathrm{~m}$ at $6 \mathrm{~m}$ depth. Concentrations of total dissolved solids in lake water determined on evaporation are in the range $200-220 \mathrm{mg} \cdot \mathrm{L}^{-1}$.

Temperature vertical profiles were measured in the water column-bottom sediment system from 20 July 2006 to the end of the experiment in March 2010 (51 profiles in all) with a pause during the 2007/2008 winter. From the outset, a ProfiLine Multi 197i (WTW) portable device with $10-\mathrm{m}$ cables enabled simultaneous measurements of the vertical profiles of conductivity, oxygen concentrations, and $\mathrm{pH}$ to be made to the bottom in the central deepest part of the lake (Fig. 1). All sensor cables were calibrated by length. Oxygen, conductivity, and $\mathrm{pH}$ sensors of the device were equipped additionally with temperature meters and allowed independent measurements. During measurement, all sensors were used without protective armor heads. On contact with the sediment surface, a significant decrease in $\mathrm{pH}$ values was used as an indicator of bottom depth. Independently, the depth of the bottom was estimated by a set of small plastic cups tied to the sensor cable above the sensor head, on their filling by sediment materials. The guaranteed measurement precision of the temperature sensors was $0.1^{\circ} \mathrm{C}$. During measurement, depending on the character of the process under study, the parameters can vary. As a rule, temperatures inside the mixed water layers were quite even and stable. However, in zones of strong gradients, temperature variations may be greater but these 
zones were easily recognized within the respective profiles. In the absence of gradients, elevated variations of standard water parameters mean also the presence of underwater flows.

During warm periods, measurements were conducted from an inflatable boat stabilized by anchor. In winter, holes were drilled in ice at the same sites.

\section{Results}

Measurements of the vertical profiles of standard water parameters $(\mathrm{pH}$, temperature, oxygen concentrations, and conductivity) carried out in the researched lake during 2006-07 showed the lake to be dimictic. The water column of the lake becomes totally oxygenated for a short period in spring at water temperatures near $4^{\circ} \mathrm{C}$ and for the long-term period in autumn due to cooling processes, inducing intense gravitational mixing. During the other times, near-bottom waters of the lake are anaerobic. In summer 2006, a zone of anaerobic waters began below the $4.5 \mathrm{~m}$ depth. It was determined that temperatures of the surface sediments of the deep bottom area reached their maximum values in autumn during the processes of the near-bottom water oxygenation. It occurred after 3 November 2006, when temperature of the sediment surface was $\sim 5.9^{\circ} \mathrm{C}$.

The temperature vertical profile measured at the end of 2006/2007 winter on 8 March 2007 (Fig. 2a) showed that according to thermal classification [5], the researched lake must be designated "moderately-warm." Thus, in that case temperatures of the near-bottom water below the $8 \mathrm{~m}$ depth were measured in the range of $3.5-3.8^{\circ} \mathrm{C}$. The respective $4^{\circ} \mathrm{C}$ isotherm was located beneath the sediment surface ( $\sim 880 \mathrm{~cm}$ depth) at $\sim 910 \mathrm{~cm}$ depth.

A course of the temperatures of the surface sediments of the deep bottom area of lake in 2008-2010 is shown in Fig. 3.

These data evidence that processes of that sediment heating during summer under conditions of stagnant temperature stratification of the water column are not effective. In that case, negative (with depth) temperature gradients in the near-bottom water are always below $\sim 0.1^{\circ} \mathrm{C} / \mathrm{m}$ (Fig. $2 b$ ).

This implies that some variations in bottom depth at the measurement site in the range of $\sim 850-900 \mathrm{~cm}$ had no effect on the accuracy of measured temperatures of the surface sediments.

In autumn, permanently cooling weather induces the processes of water column gravitational mixing, which reaches finally near-bottom waters, and more effective heating of the sediments of the deep bottom area begins (Fig. 2c).

The amount of heat stored in surface sediments during that period depends on the temperature of the water column and the duration of the process. Apparently these factors are related to the particular meteorological situation in autumn. Despite the large amount of data revealing the physical effect on the biological and chemical regimes in lakes, there is still insufficient understanding - both qualitative and quantitative - of how a lake ecosystem would be affected
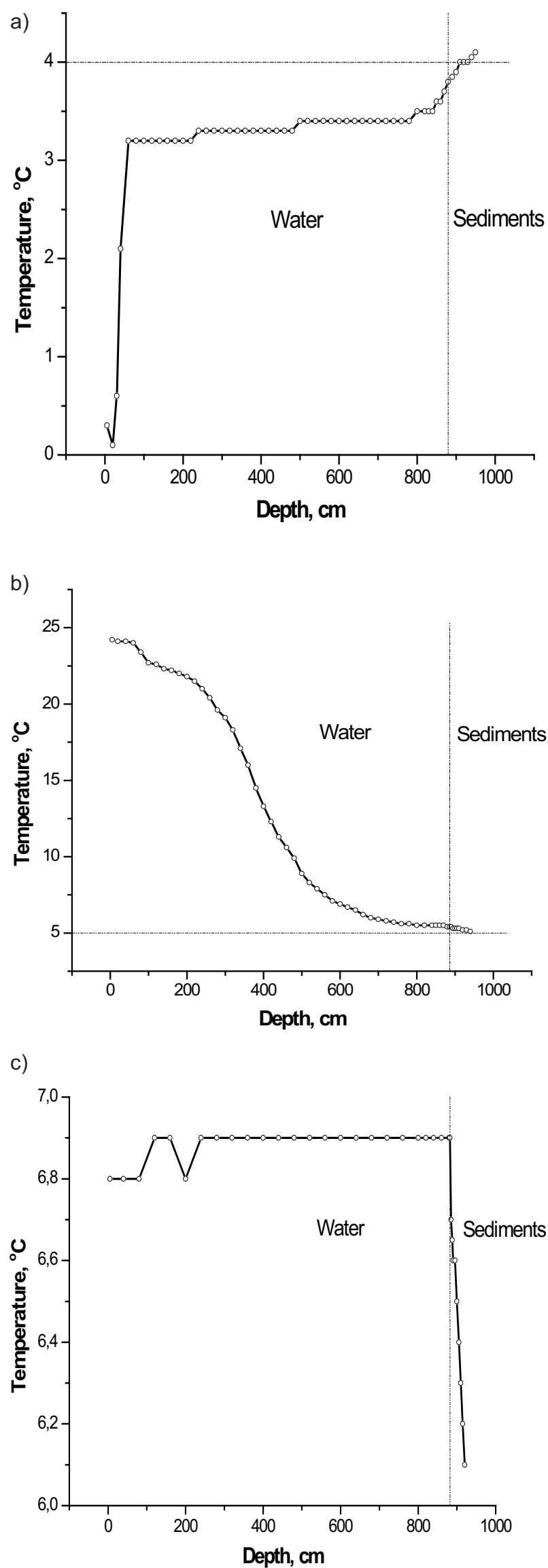

Fig. 2. Temperature vertical profile (depth of the bottom $-\sim 880$ cm) measured on: 8 March 2007 (a), 25 July 2008 (b), 7 November 2008 (c). 
by changes in the lake temperature and mixing conditions due to changes in atmospheric forcing [8]. In Fig. 3, maximum temperatures of the surface sediments of the deep bottom area in 2008 and 2009 were measured on 7 November and on 19 October, respectively. Mean diurnal temperature courses during three last months of 2008 and 2009 are shown in Fig. $4(\mathrm{a}, \mathrm{b})$.

It is easy to see that the heating period after 7 November 2008 was very short: during the next 10 days, mean diurnal temperatures of ambient air were lower than those of the water column and incited their further decrease.

Thus, on 18 November 2008 temperature of the surface sediments was only $5.2^{\circ} \mathrm{C}$, meaning that processes of sediment cooling began (Fig. 5a).

On the other hand, such processes of sediment heating in 2009 began earlier (on 19 October) and lasted for a significantly longer time. During a further week, mean diurnal temperatures of the ambient air increased, inducing stagnant temperature stratification of the water column and continuation of the sediment heating processes providing the spread of elevated temperatures to larger depths. Under cooling weather conditions, on 7 December 2008 (Fig. 4a), a positive (with the depth) temperature gradient was formed in the water column, Fig. 6 (a). In that vertical profile, a $4^{\circ} \mathrm{C}$ isotherm was located at some $35 \mathrm{~cm}$ depth below the sediment surface. A further decrease in ambient air temperatures induced the formation of the $2 \mathrm{~cm}$ ice cover on 14 December 2008. The same thickness of the ice cover was measured on 13 December 2009. However, conditions of the foregoing weather from 15 November until 6 December 2009 allowed temperatures of the surface sediments to vary in the range $4-4.2^{\circ} \mathrm{C}$. Different amounts of heat stored in sediments of the deep bottom area until the moment of the formation of ice in 2008 and 2009 influenced the thermal situation in the near-bottom water in the 2008/2009 and 2009/2010 winters.

Thus, in the vertical profile measured on 12 March 2009 (Fig. 5b), temperature of the near-bottom water raised from $3.6^{\circ} \mathrm{C}$ at $800 \mathrm{~cm}$ depth up to $\sim 3.9^{\circ} \mathrm{C}$ at the sediment surface ( $\sim 885 \mathrm{~cm}$ depth), approving the lake for classification as "moderately-warm."

However, the respective vertical profile measured on 14 March 2010 (Table 1) showed a rather different feature. Temperature of the near-bottom water in that profile increased from $3.9^{\circ} \mathrm{C}$ at $800 \mathrm{~cm}$ depth to $4.2^{\circ} \mathrm{C}$ at the sediment surface ( $\sim 880 \mathrm{~cm}$ depth), supposing the lake as belonging to the "super warm" type according to Kilkus thermal classification [5]. Vertical profiles of $\mathrm{pH}$ and conductivity measured on 14 March 2010 (Table 1) were used below to evidence the presence of the admixture of highly mineralized water from the bottom feeding sources in the near-bottom water layer of the deep bottom area of the lake.

\section{Discussion}

Measurements carried out in the researched lake show that, depending on the amount of heat accumulated in sediments of the deep bottom areas of the lake until the begin-

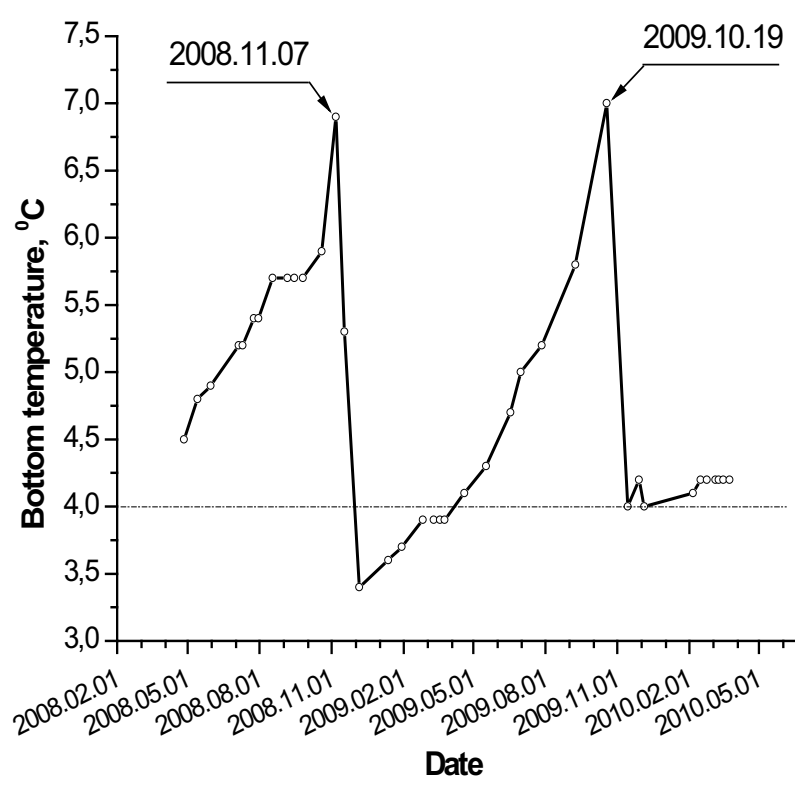

Fig. 3. A course of the temperatures of the surface sediments of the deep bottom area in 2008-10.
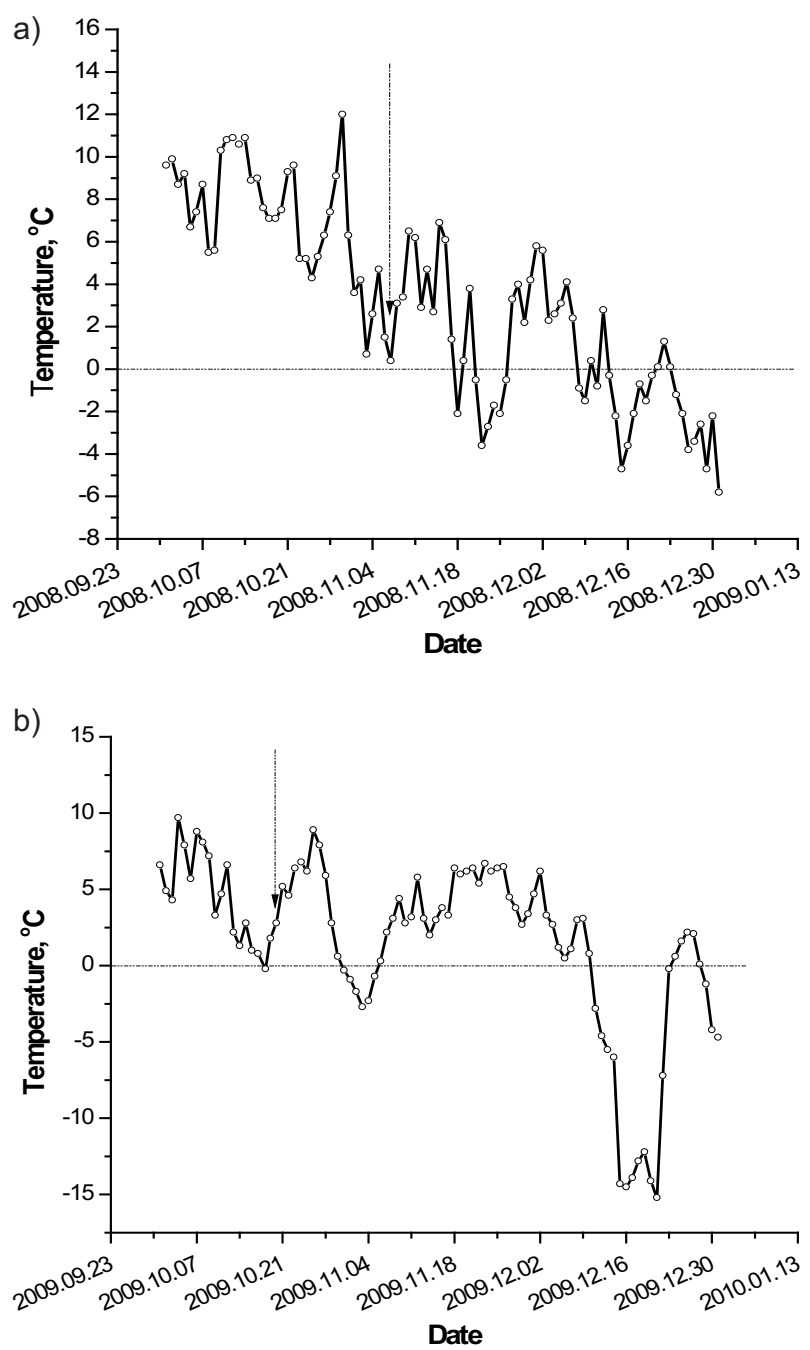

Fig. 4. Courses of mean diurnal temperatures of the ambient air during the last three months of 2008 (a) and 2009 (b); dotted arrows - dates of the measurements of the temperature vertical profiles: 7 November 2008 (a) and 19 October 2009 (b). 
ning of winter, the lake may be designated "super-warm" or "moderately-warm." Therefore, it seems that thermal classification is more or less formal.

In other words, it does not denote multiple consequences to the thermal regime of the near-bottom waters of the thermodynamic processes related to heat redistribution in the lacustrine system thermally isolated by the ice cover from the ambient air. It is evident that in deeper lakes an additional heating of the sediments of the deep bottom areas becomes problematic. In deeper lakes, that process takes place at lower temperatures and for a shorter period of time. Ultimately, at some lake depth, processes of the gravitational mixing of the water column can reach the deepest bottom areas at temperatures related to maximum water density $\left(\sim 4^{\circ} \mathrm{C}\right)$. In that case, a short-term oxygenation of the whole water column is not related to any additional heating of the sediments of the deep bottom areas of the lake. Apparently, such type of deep lakes with the absence of the processes of heat redistribution between the deep bottom areas and the water column are classified as "warm."

a)
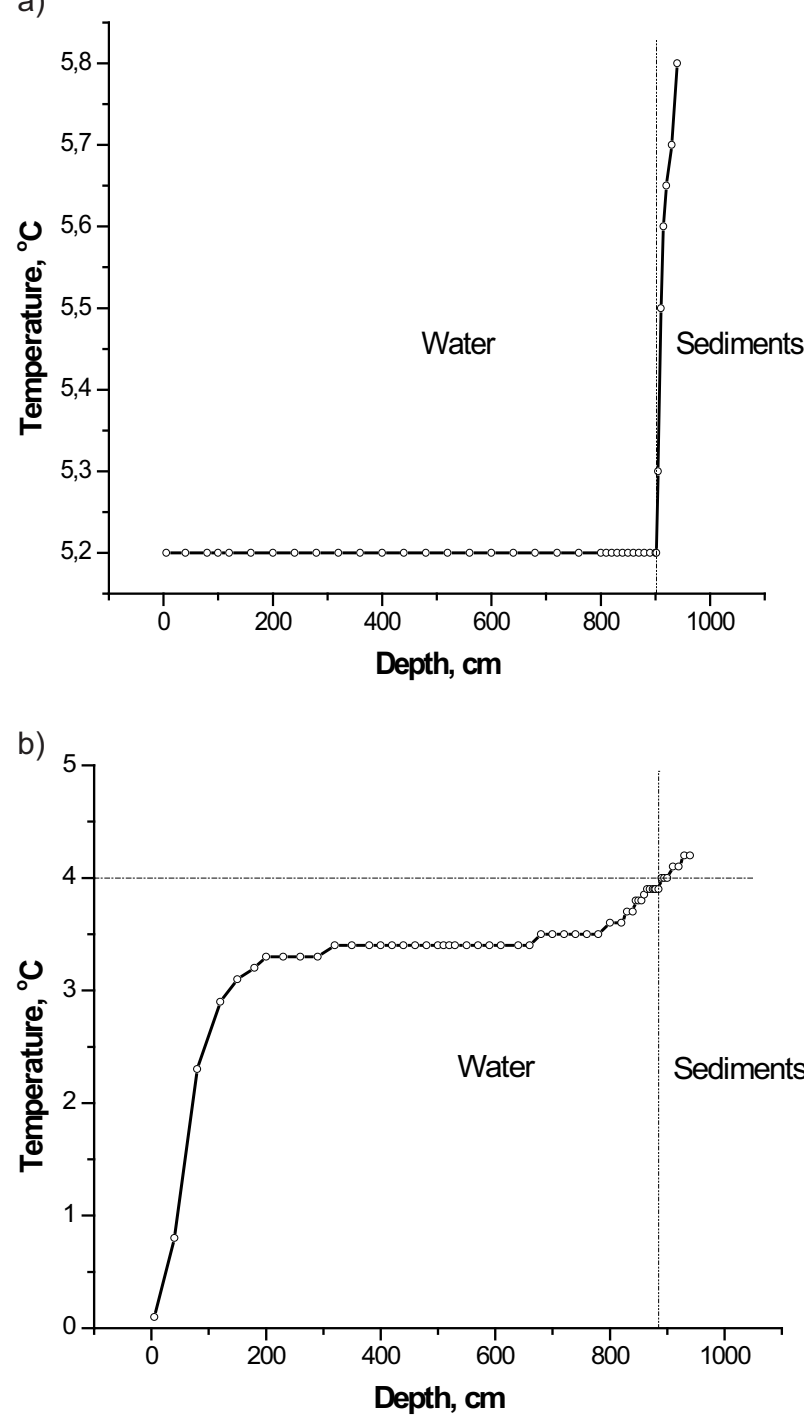

Fig. 5. Temperature vertical profile measured on 18 November 2008: depth of the bottom - 902 cm (a); 12 March 2009, depth of the bottom $-\sim 885 \mathrm{~cm}$ (b).
Table 1. Vertical profiles of temperature, $\mathrm{pH}$, and conductivity measured on 11 March 2010; depth of the bottom $-880 \mathrm{~cm}$.

\begin{tabular}{|c|c|c|c|c|}
\hline $\begin{array}{l}\text { Depth } \\
{[\mathrm{cm}]}\end{array}$ & $\begin{array}{c}\text { Temperature } \\
{\left[{ }^{\circ} \mathrm{C}\right]}\end{array}$ & $\mathrm{pH}$ & $\begin{array}{l}\text { Conductivit } \\
\mathrm{y}\left[\mu \mathrm{S} \cdot \mathrm{cm}^{-1}\right]\end{array}$ & \\
\hline 5 & 0.1 & 7.72 & 195 & \multirow{22}{*}{ Water } \\
\hline 50 & 0.5 & 7.6 & 202 & \\
\hline 80 & 1.9 & 7.48 & 225 & \\
\hline 110 & 2.7 & 7.44 & 232 & \\
\hline 140 & 3.1 & 7.38 & 237 & \\
\hline 170 & 3.25 & 7.36 & 252 & \\
\hline 200 & 3.6 & 7.31 & 263 & \\
\hline 230 & 3.6 & 7.31 & 272 & \\
\hline 260 & 3.7 & 7.29 & 306 & \\
\hline 320 & 3.8 & 7.27 & 309 & \\
\hline 380 & 3.8 & 7.24 & 311 & \\
\hline 440 & 3.8 & 7.21 & 313 & \\
\hline 500 & 3.8 & 7.16 & 314 & \\
\hline 560 & 3.8 & 7.12 & 315 & \\
\hline 620 & 3.8 & 7.08 & 316 & \\
\hline 680 & 3.8 & 7.07 & 317 & \\
\hline 740 & 3.9 & 7.06 & 318 & \\
\hline 800 & 3.9 & 7.05 & 321 & \\
\hline 840 & 4.0 & 7.07 & 332 & \\
\hline 860 & 4.1 & 7.15 & 366 & \\
\hline 870 & 4.2 & 7.11 & 438 & \\
\hline 880 & 4.2 & 7.00 & 559 & \\
\hline 885 & 4.2 & 6.92 & 570 & \multirow{6}{*}{ Sediments } \\
\hline 890 & 4.3 & 6.88 & 560 & \\
\hline 895 & 4.3 & 6.85 & 551 & \\
\hline 900 & 4.3 & 6.82 & 540 & \\
\hline 910 & 4.4 & 6.78 & 544 & \\
\hline 920 & 4.4 & 6.76 & 553 & \\
\hline
\end{tabular}

However, one of the most interesting questions is related to the existence of the "super-warm" type of lake and courses of the thermal regime of their near-bottom waters with the elevated temperatures above $4^{\circ} \mathrm{C}$. There are two neighboring lakes near researched Lake Tapeliai: Lake Juodis $\left(54^{\circ} 46^{\prime} 49^{\prime \prime} \mathrm{N}, 25^{\circ} 26^{\prime} 29^{\prime \prime} \mathrm{E}\right)$ and Red Lake $\left(54^{\circ} 46^{\prime} 11^{\prime \prime} \mathrm{N}\right.$, $\left.25^{\circ} 27^{\prime} 23^{\prime \prime} \mathrm{E}\right)$. Temperatures of the near-bottom waters in winter in those lakes are always some degrees higher than $4^{\circ} \mathrm{C}[9,10]$. Thermohalinic stability of the water column implies that in such cases, mineralization of the nearbottom waters must be elevated. There are a number of reasons for such phenomenon: 
a) an additional release to the near-bottom waters under anaerobic conditions of water-soluble products related to sediment organic decomposition (including dissolution of carbonates and reduced iron and manganese ions)

b) additional mineralization of near-bottom waters due to inflows from the bottom feeding sources

c) intrusions of sediment interstitial liquids due to buoyancy effects in the surface sediment layers with strong temperature gradients.

At first, Turner [11] presented experimental and theoretical evidence of the latter effects. The temperature vertical profile presented in Fig. 5 (a) proves also the presence of strong temperature gradients in the surface sediments of deep bottom areas of researched Lake Tapeliai during the cooling of the water column. Moreover, a shift of the $4^{\circ} \mathrm{C}$ isotherm beneath the sediment surface in winter by some tens of $\mathrm{cm}$ may be also due to the convective motions in surface sediments induced by buoyancy forces. A layered structure of the water column clearly seen on the vertical profiles of temperature, $\mathrm{pH}$, oxygen concentration, and conductivity (Figs. 6 a-d) evidences the effects of buoyancy forces [11]. Apparently, these processes must be the objects of future studies. They are also of great concern due to their importance in estimating the lake as a secondary source of radiocesium for flushing waters. It is known $[12,13]$ that radiocesium activity concentrations in anaerobic interstitial water of surface sediments are significantly larger than those in the near-bottom water. Therefore, intrusions of

a)
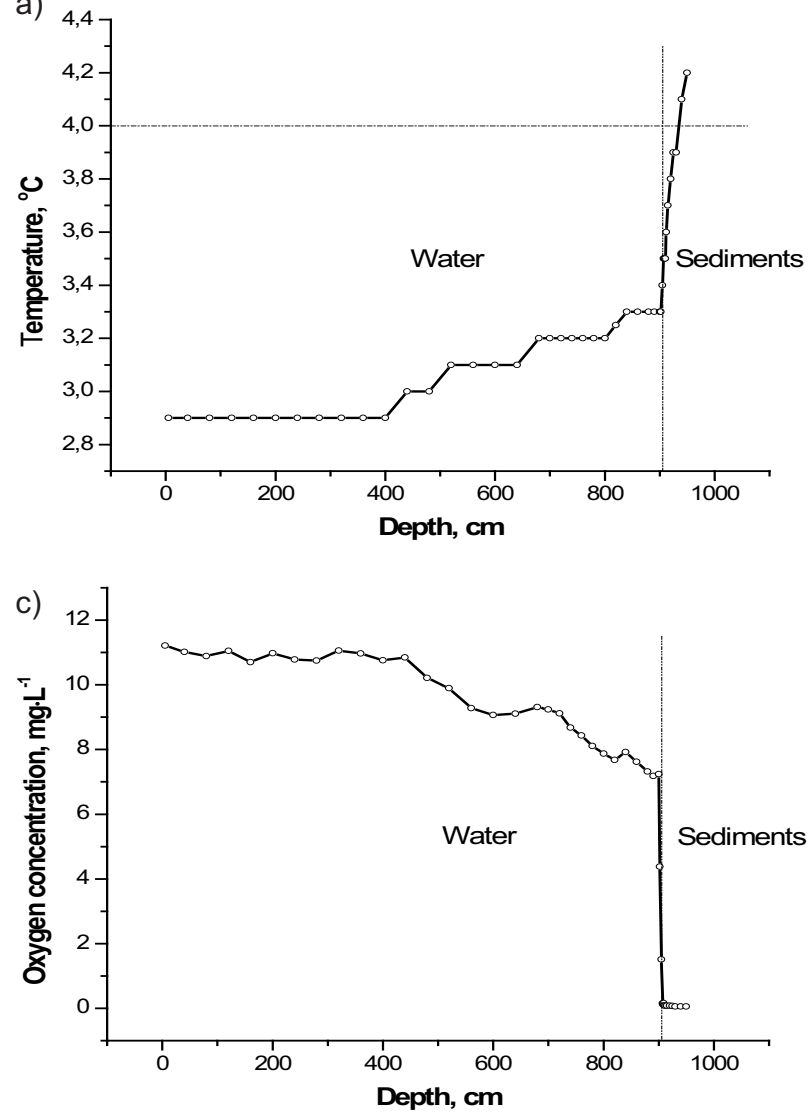

interstitial liquids to the near-bottom areas must induce elevated radiocesium concentrations in the respective waters.

In our present study, we can state that all three abovementioned reasons of highly mineralized near-bottom water might be possible. They are related to the formation of the long-term anaerobic zone in the lake in winter and strong temperature gradients in the surface sediments during cooling processes as well as the presence of the bottom-feeding sources. Likely, the presence of highly mineralized water from the bottom-feeding sources in our case was proved experimentally. The specific features of the water from the bottom-feeding sources in the southern terrace of Lake Tapeliai can be seen in Table 2. As in the latter case measured on 14 March 2010 (Table 2), vertical profiles of $\mathrm{pH}$ in the area of bottom feeding sources are typical of its elevated values at the near-bottom water-sediment surface interface. Ordinarily that effect is related to the high photosynthetic activity of green algae covering surface sediments $[14,15]$. However, the respective vertical profile of oxygen concentrations (not shown) evidenced the beginning of the anaerobic zone below the $230 \mathrm{~cm}$ depth.

According to the temperature vertical profile (Table 2), sediment temperatures increase from $4^{\circ} \mathrm{C}$ at the sediment surface with the depth. The conductivity vertical profile (Table 2) shows that zones of elevated $\mathrm{pH}$ and conductivities below the sediment surface coincide. It implies that a bottom flow of the alkaline (elevated $\mathrm{pH}$ ) and of the elevated mineralization (conductivity peak in some profiles was up to $390 \mu \mathrm{S} \cdot \mathrm{cm}^{-1}$ ) water has soaked the surface sedi-

b)
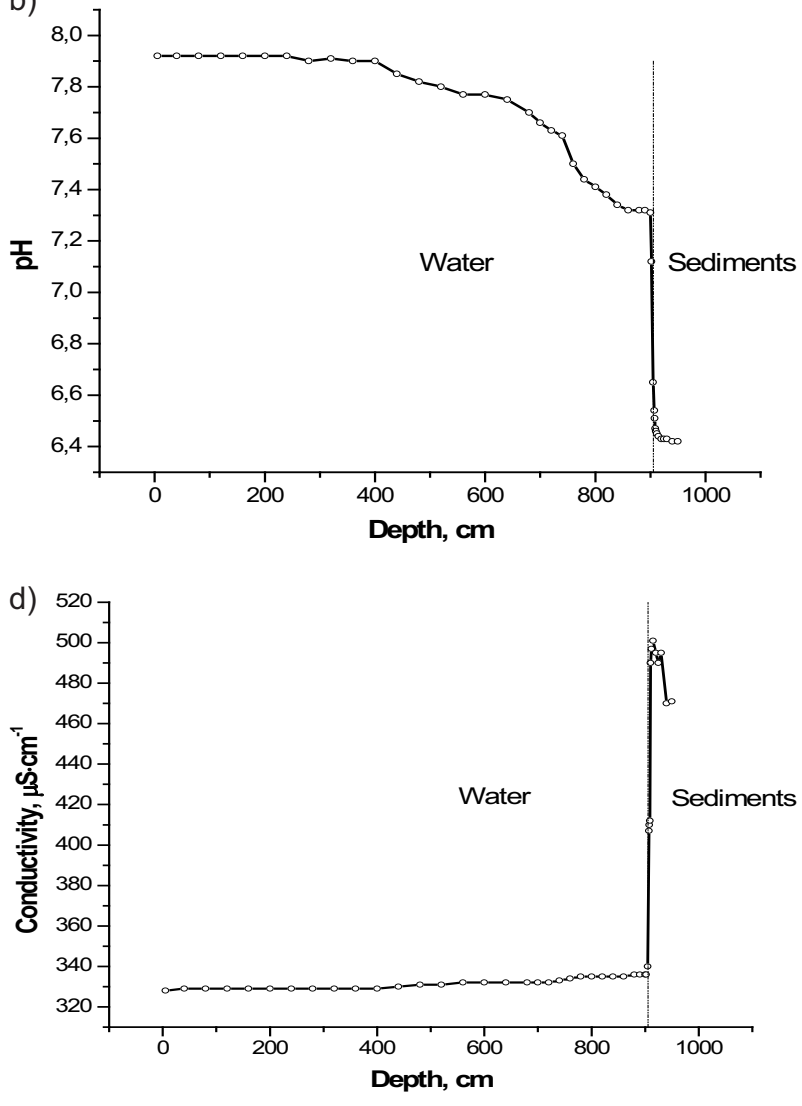

Fig. 6. Evidence of the layered structure of the water column measured on 7 December 2008: vertical profiles of temperature (a), $\mathrm{pH}$ (b), oxygen concentrations (c), and conductivity (d); depth of the bottom - 905 cm. 
Table 2. Vertical profiles of temperature, $\mathrm{pH}$, and conductivity measured on 14 March 2010 at the lake southern terrace in the area of bottom-feeding sources; depth of the bottom $-\sim 485 \mathrm{~cm}$.

\begin{tabular}{|c|c|c|c|}
\hline $\begin{array}{c}\text { Depth } \\
{[\mathrm{cm}]}\end{array}$ & $\begin{array}{c}\text { Temperature } \\
{\left[{ }^{\circ} \mathrm{C}\right]}\end{array}$ & $\mathrm{pH}$ & $\begin{array}{c}\text { Conductivity } \\
{\left[\mu \mathrm{S} \cdot \mathrm{cm}^{-1}\right]}\end{array}$ \\
\hline 5 & 0.1 & 7.41 & 245 \\
\hline 50 & 0.1 & 7.47 & 252 \\
\hline 80 & 1.4 & 7.46 & 243 \\
\hline 110 & 2.4 & 7.43 & 246 \\
\hline 140 & 2.8 & 7.41 & 311 \\
\hline 170 & 3.0 & 7.39 & 312 \\
\hline 200 & 3.3 & 7.37 & 313 \\
\hline 230 & 3.5 & 7.35 & 314 \\
\hline 260 & 3.7 & 7.34 & 317 \\
\hline 290 & 3.75 & 7.33 & 317 \\
\hline 320 & 3.8 & 7.34 & 317 \\
\hline 350 & 3.8 & 7.27 & 318 \\
\hline 380 & 3.8 & 7.29 & 318 \\
\hline 410 & 3.8 & 7.28 & 318 \\
\hline 440 & 3.8 & 7.27 & 318 \\
\hline 470 & 3.8 & 7.31 & 319 \\
\hline 485 & 4.0 & 7.68 & 337 \\
\hline 488 & 4.0 & 8.22 & 374 \\
\hline 490 & 4.0 & 7.85 & 373 \\
\hline 495 & 4.1 & 7.72 & 376 \\
\hline 500 & 4.2 & 7.65 & 372 \\
\hline 505 & 4.3 & 7.58 & 370 \\
\hline 510 & 4.3 & 7.48 & 362 \\
\hline 515 & 4.4 & 7.40 & 347 \\
\hline 520 & 4.5 & 7.28 & 327 \\
\hline 525 & 4.6 & 7.22 & 322 \\
\hline 530 & 4.6 & 7.12 & 317 \\
\hline 535 & 4.7 & 7.01 & 315 \\
\hline
\end{tabular}

ments, providing conservation effects onto sediment organics. Likely, highly mineralized alkaline water from the bottom feeding sources was responsible for the formation of the near-bottom water layer with elevated mineralization and $\mathrm{pH}$ values in deep bottom areas of Lake Tapeliai. That layer is distinctly seen in the respective vertical profiles of $\mathrm{pH}$ and conductivity (Table 1). Measurements in the nearbottom water layer were followed by rather large variations of standard parameters, which for $\mathrm{pH}$ values were in the range of \pm 0.03 . In the respective vertical profile (Table 1), maximum $\mathrm{pH}$ values were used.
An important role of highly mineralized water of the bottom feeding sources in the processes of additional sediment heating under conditions of the water column gravitational mixing in autumn must be also emphasized. Apparently, gravitational mixing of the water column in autumn at higher temperatures than those of the surface sediments must be followed by the formation of the temperature-stratified near-bottom water layer hindering sediment surface heating. However, measurements show that such heating in our case is possible. This is likely due to the accumulation in the near-bottom water layer of the deepest lake areas of denser highly mineralized preheated waters from the bottom-feeding sources located in shallower areas of the lake.

However, under conditions of the weak thermohalinic stratification of the water column in Lake Tapeliai in winter, we cannot ignore the possibility of large-scale vertical convective currents [3], which may be confined only within the depth range with low temperature gradients (the range of 3-8.5 m depths). Apparently, the involvement of under-ice water with reduced conductivities (Table 1) in the large-scale vertical convective currents would lead to a respective decrease in their values in the near-bottom water layer. On the contrary, measurement data show a significant increase in conductivity of the near-bottom water with depth. However, it seems very likely that large-scale convective currents as well as alkaline water inflows from the bottom-feeding sources may be responsible together for the formation of the near-bottom water layer with the elevated $\mathrm{pH}$ values. We think that this must be the object of future studies.

\section{Conclusions}

The thermal regime of the near-bottom water of the deep bottom areas of the researched Lake Tapeliai in winter depends on the amount of heat accumulated in those sediments during warm seasons. The formation of the regime is related to processes of that heat redistribution between sediments of the deep bottom areas and the water column. Temperatures of the surface sediments of the deep bottom areas of the lake reach their maximum values in autumn during the processes of the near-bottom water oxygenation due to the gravitational mixing of the water column. A thermal classification of lakes, according to temperatures of the near-bottom waters in winter, is too formal and does not denote multiple consequences to the thermal regime of the near-bottom waters of the thermodynamic processes related to heat redistribution in the lacustrine system thermally isolated by the ice cover from the ambient air.

\section{References}

1. DAUBARIENĖ J., VALIUŠKEVIČIUS G. Lake classifications used in Lithuania: system and employment possibilities. Geografija 45, (2), 111, 2009 [In Lithuanian]. 
2. MCELARNEY Y. R., RIPPEY B. A comparison of lake classifications based on aquatic macrophytes and physical and chemical water body descriptors. Hydrobiologia 625, 195, 2009.

3. KIRILLIN G., ENGELHARDT CH., GOLOSOV S., HINTZE TH. Basin-scale internal waves in the bottom boundary layer of ice-covered Lake Müggelsee, Germany. Aquatic Ecology 43, (3), 641, 2009.

4. DUNALSKA A. J., OSZCZAK B., TANAJEWSKI D., GOMUŁKA P. Effect of increased hypolimnion water temperature on stability of thermal profiles in stratified lakes. Global Journal on Advances in Pure \& Applied Sciences [Online] 1, 608, 2013.

5. KILKUS K. Thermal structures of dimictic lakes. Vilnius: Vilnius University, 200, 2000.

6. TARASIUK N., MOISEJENKOVA A., KOVIAZINA E., KARPICZ R., ASTRAUSKIENE N. On the radiocesium behavior in a small humic lake (Lithuania). Nukleonika 54, (3), 211, 2009.

7. GRIŽIENĖ G., JABLONSKIS J., JANUŠEVIČIUS S., JURGELEVIČIENĖ I., JURGELĖNAITĖ A., JUŠKIENE் A., KRIAUČIŪNAS R. Hydrography of the Neris River. Energetika 1, 20, 1993 [In Lithuanian].

8. GOLOSOV S., TERZHEVIK A., ZVEREV I., KIRILLIN G., ENGELHARDT C. Climate change impact on thermal and oxygen regime of shallow lakes. Tellus A 64, 1, 2012.
9. TARASIUK N., KOVIAZINA E., KUBAREVICIENE V., SHLIAHTICH E. On the radiocesium carbonate barrier in organics- rich sediments of Lake Juodis, Lithuania. J. Environ. Radioactiv. 93, (2), 100, 2007.

10. TARASIUK N., KOVIAZINA E., KUBAREVICIENE V. On seasonal variations of radiocesium speciation in the surface sediments of Lake Juodis, Lithuania. J. Environ. Radioactiv. 99, (1), 199, 2008.

11. TURNER J. S. Buoyancy effects in fluids. Cambridge: University Press, 367, 1973.

12. COMANS R. N. J., MIDDELBURG J. J., ZONDERHUIS J., WOITTIEZ R. W., DE LANGE G. J., DAS H. A., VAN DER WEIJDEN C. H. Mobilization of radiocesium in pore water of lake sediments. Nature, 339, (6223), 367, 1989.

13. SMITH J. T., COMANS R. N. J. Modelling the diffusive transport and remobilization of ${ }^{137} \mathrm{Cs}$ in sediments: The effects of sorption kinetics and reversibility. Geochim. Cosmochim. Ac. 60, 995, 1996.

14. TARASIUK N., MOISEJENKOVAA., KOVIAZINA E. On the mechanism of the enrichment in radiocesium of nearbottom water in Lake Juodis, Lithuania. J. Environ. Radioactiv. 101, (10), 883, 2010.

15. MOISEJENKOVA A., TARASIUK N., KOVIAZINA E., MACEIKA E., GIRGŽDYS A. ${ }^{137} \mathrm{Cs}$ in Lake Tapeliai, Lithuania. Lith. J. Phys. 52, (3), 238, 2012. 